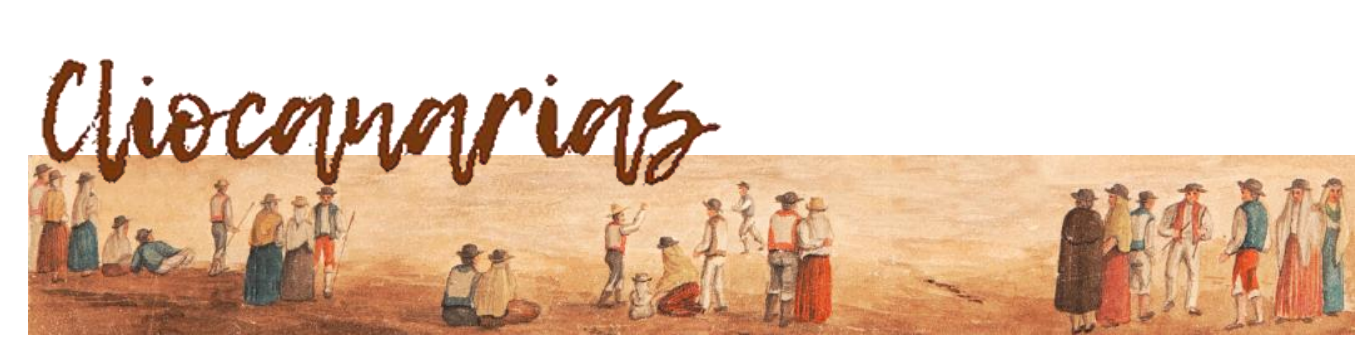

ISSN 2695-4494

https://doi.org/10.53335/cliocanarias.2021.3.29

\title{
ALGUNAS DATAS INÉDITAS DEL REPARTIMIENTO DE GRAN CANARIA
}

SOME UNPUBLISHED DATAS OF THE REPARTIMIENTO OF GRAN CANARIA

Lorenzo SANTANA RODRÍGUEZ*

RESUMEN: Se publica un conjunto de trece datas de repartimiento inéditas de la isla de Gran Canaria a través de un traslado presentado en su momento ante el tribunal del Santo Oficio de Canarias, en cuyos fondos se ha conservado, habiendo desaparecido sus correspondientes originales.

PALABRAS CLAVE: datas, repartimientos, Inquisición, Gran Canaria.

ABSTRACT: A set of thirteen unpublished datas of the repartimiento of the island of Gran is published through a transfer presented at the time before the court of the Santo Oficio of the Canary Islands, in whose funds it has been preserved, having disappeared its corresponding originals.

KEYwORDS: datas, repartimientos, Santo Oficio, Gran Canaria

\section{Introducción}

Debido a la desaparición de la mayor parte de los registros de los repartimientos que se hicieron en la isla de Gran Canaria tras su conquista por la Corona de Castilla, adquiere más importancia el conocimiento de algunos de ellos gracias a las copias autorizadas que se hicieron con posterioridad a su concesión.

Este es el caso que nos ocupa ahora, en el que publicamos un grupo de trece repartimientos o datas concedidas en diferentes fechas a Juan de San Juan, Alonso García, albañil, y Francisco de Cabrejas, conquistadores de la dicha isla.

Todas ellas fueron copiadas de sus respectivos originales en un traslado autorizado el 12 de mayo de 1588 por Alonso de Balboa, escribano público y del Cabildo de la isla de Gran Canaria, institución esta que custodiaba en su archi

\footnotetext{
* Graduado en Historia del Arte. C. e.: lorenz199@hotmail.com.
} 
vo concejil estos registros, a petición de Bernardino de San Juan, regidor de la mencionada isla, como a nieto y uisnieto que dixo ser de los contenidos en este testimonio.

Posteriormente, el 10 de octubre de 1591, este traslado fue presentado, junto con otros documentos, ante el tribunal del Santo Oficio de la isla de Gran Canaria por el doctor Juan de San Juan Toscano, racionero de la catedral de Canaria, con el fin de que sirviera para atestiguar la limpieza de su sangre, alegando de forma implícita la condición cuasinobiliaria de su familia por descender de conquistadores de la isla ${ }^{1}$.

De este traslado autorizado se realizó otro simple, que es el quedó en el archivo del Santo Oficio de Canarias, y es ahí donde lo hemos encontrado. Se encuentra actualmente en el Archivo Histórico Nacional, habiéndolo podido localizar y estudiar a través del portal PARES, cuya utilidad para los investigadores es siempre de agradecer, sobre todo cuando incorpora, como en este caso, las imágenes digitalizadas.

Al tratarse de datas inéditas, pues no las hemos encontrado entre aquellas cuya existencia y texto ya eran conocidas ${ }^{2}$, hemos optado por publicar este traslado en forma integra.

\section{APÉNDICE DOCUMENTAL: LAS DATAS}

Archivo Histórico Nacional, Inquisición 1.832, expediente 4, folios 44v-47r (numeración a lápiz).

${ }^{3}$ Yo, Alonso de Balboa, escrivano mayor del Cabildo e público desta isla [45r / /] de la Gran Canaria por su magestad, doi fe y uerdadero testimonio a los que la 4 presente uieren que en los libros y repartimientos que se hizieron de tierras y aguas a los conquistadores $y$ pobladores que vinieron a conquistar y poblar esta dicha isla, entre otros repartimientos parese por los dichos libros que se dio y repartió a Juan de San Juan, y Alonso Garçía, alvanir, su suegro, y a Francisco de Cabrejas, conquistadores, los repartimientos de tierras y aguas siguientes:

5 Juan de San Juan, conquistador, este dicho dia, junto con la suerte del dicho Alonso de Aréualo, ensima de un sercado de Ybone de Armas, se hiso un pedaso de tierra ques vaxo del dicho camino, y se a de regar con la dicha asequia de la uilla, en que uvo dos mill y quinientas y ochenta y

\footnotetext{
${ }^{1}$ Archivo Histórico Nacional, Inquisición, leg. 1.832, expediente 4, folios 42r-47r (numeración a lápiz).

2 JIMÉNEZ SÁNCHEZ, Sebastián: Primeros repartimientos de tierras y aguas en Gran Canaria, Talleres tipográficos de Falange, Las Palmas de Gran Canaria, 1940: Repartimientos de Gran Canaria, edición, transcripción y notas: Manuela RONQUILLO y Eduardo AZNAR VALLEJO, Ediciones del Cabildo Insular de Gran Canaria, Museo Canario, Las Palmas de Gran Canaria, 1998; GAMBÍN GARCÍA, Mariano: "Los primeros repartimientos de Gran Canaria. Un replanteamiento a partir de nuevos datos", Anuario de Estudios Atlánticos, n. ${ }^{\circ}$ 60, 2014, pp. 239268; Datas de Gran Canaria. Documentos para su estudio, Archivo Histórico Provincial de Las Palmas, Las Palmas de Gran Canaria, 2015.

${ }^{3}$ Nota marginal: Fee del escriuano de Conçejo de çiertos repartimientos de tierras y aguas.

4 Tachado: $c$.

${ }^{5}$ Nota marginal: Repartimiento.
} 
nueve brasas. A la qual dicha tierra, e a una lançada de tierra que junto con ella se dio a Martín d'Escalante, se dio agua de media suerte de tierra. $Y$ tiene estos dos pedasos el seruisio por el camino de la Vega e no por otra parte.

${ }^{6}$ Después desto, en nueve dias del mes de henero, año del Nasimiento de Nuestro Señor e Saluador Jesucristo de mill e quatrosientos y nouenta años, el dicho governador Pedro de Vera dio al dicho Juan de San Juan media suerte de tierra en la Uega de medio del lugar de Telde, que primeramente fue dada a Alonso Garçía, aluanir, su suegro, porque el dicho Alonso Garçía, aluañir, se fue a uiuir desta isla a otra parte, como está asentado a las çiento $y$ treinta $y$ sinco fojas.

${ }^{7}$ Alonso Garçía, aluanir, conquistador. Este dicho dia, junto a la dicha peonía que se dio al dicho Alonso de Toledo se hiso vna suerte de tierra de regadio de sinco lançadas, que ternía por fontera de anchura por uera del dicho camino treinta y tres brasas. Diéronsela los dichos repartidores al dicho Alonso Garçía, alvañir, conquistador.

8 Diósele más al dicho Alonso Garçía, alvanir, media [45v//] suerte de tierra en la uega del medio, junto a un pedaso de tierra que se dio a Visente Taborda. Y tiene por detrás el dicho camino que va a Melenara.

${ }^{9}$ Diósele más vna cueva junto a vnos casarones derribados, e más una casa con un casarón sercado en un sitio. Diósele más para vna guerta vna quarta de tierra en valle poblado, lo qual se dio a Martín de Xerés, como está asentado a çiento y quarenta y sinco hojas.

10Juan de San Juan. En tres de setiembre de mil y quinientos y dos años, el noble cauallero Antonio de Torres, gouernador y justiçia mayor desta isla de la Gran Canaria por el rei y la reina, nuestros señores, en presençia de nos, Gonsalo de Burgos, escrivano público y del Cabildo desta isla de la Gran Canaria, e de Juan de Ariñez, escrivano público della, repartiendo tierras de riego en Firgas, debaxo del açequia prinsipal del dicho Firgas, dio e pagó a Juan de San Juan, e a sus herederos por él, veinte y sinco mill e setenta maravedis de buena moneda de Castilla que paresió por vna copia firmada de Rodrigo de Alcoçer quel dicho Juan de San Juan uvo de auer del tienpo que siruió en la conquista desta isla. Los quales dichos maravedis le dio y pagó en tierras de riego en el dicho Firgas. Que fueron apresiadas cada suerte en quarenta $y$ un mill e dosientos e sinquenta maravedis de buena moneda de Castilla, que son desta moneda de Canaria sinquenta y sinco mill maravedis. $Y$ son linderos de las dichas tierras, de la una parte tierras de Rodrigo Priuado, y de la otra parte tierras de Rui Gonsales.

\footnotetext{
6 Nota marginal: Otro.

7 Nota marginal: Otro.

8 Nota marginal: Idem.

9 Nota marginal: Idem.

10 Nota marginal: Idem.
} 
${ }^{11}$ A los menores de Juan de San Juan se le confirmó tres arançadas de tierra de riego que son en el heredamiento de Firgas. Que an por linderos de la una parte tierras que fueron de Fernando de $\mathrm{Ma}$ - [46r//] chicao, e de la otra parte tierras del bachiller Alonso de Belmonte, e de la otra parte el asequia del dicho heredamiento. Las quales dichas tres ${ }^{12}$ lansadas de tierra de riego se an de regar con el agua del asequia del dicho heredamiento de Firgas por sus dulas, cada dula de treinta en treinta dias. E a de auer para las regar tres oras de agua, y a cada dula regando las dichas tres oras con una asada de agua.

${ }^{13}$ Fransisco de Cabrejas, conquistador. Este dicho dia, junto a la dicha media suerte que se hiso e se dio al dicho Garçía de Morales se fiso una media suerte de tierra, en que uvo dos alançadas, que tienen de ancho por la parte de ençima vera del dicho sercado, e por la parte de abaxo vera del dicho camino treinta e una brasas y media. La qual se dio al dicho Fransisco de Cabrejas. Que se a de regar como dicho es.

${ }^{14} \mathrm{En}$ tres dias de setiembre de mill y quinientos y dos años, el noble cavallero Antonio de Torres, governador e justiçia mayor desta isla de la Gran Canaria por el rei y reina, nuestros señores, en presençia de nos, Gonsalo de Burgos, escrivano público y del Cabildo desta isla de la Gran Canaria, e de Juan de Ariñez, escrivano público della, repartiendo tierras de riego en Firgas, debaxo del açequia prinsipal del dicho Firgas, dio e pagó a Francisco de Cabrejas veinte $y$ un mill $y$ ochoçientos e sinquenta $y$ dos maravedis de buena moneda de Castilla, que parese por una copia firmada de Rodrigo de Alcoçer quel dicho Fransisco de Cabrejas uvo de auer del tienpo que siruió en la conquista desta isla. Los quales dichos marauedis le dio e pagó en tierras de riego en la dicha Firgas. Que fueron apresiadas cada suerte en quarenta $y$ un mill $y$ dosientos $y$ sinquenta maravedis de buena moneda, que son desta moneda de Canaria, sinquenta $y$ sinco mill maravedis. $Y$ son por linderos de las dichas tierras, de una parte tierras de Fernando de Prado, e de otra tierras de Alonso Lebrón.

[46v//] 15Fransisco de Cabrejas, vezino desta isla. Se le confirmó dos alançadas y media de tierras de riego, que son en el heredamiento de Firgas, que an por linderos de la vna parte tierras de Alonso Lebrón, e de la otra parte tierras del menor de Fernando de Prado, e de la otra parte tierras de Juan de Ariñez. Las quales se an de regar con el agua del asequia prinsipal del dicho heredamiento por sus dulas, de treinta en treinta diaz, e a de auer en cada dula dos oras y media de agua, regando las dichas dos oras e media de agua con vna asada de agua ${ }^{16}$ Otrosi, se le confirmó otra media suerte de tierra de riego, y es en la uega de San Sebastián, que a por linderos de la una parte tierras del licenciado Fernando de Aguayo, e

\footnotetext{
11 Nota marginal: Idem.

12 Enmendado sobre: tierras.

13 Nota marginal: Idem.

${ }^{14}$ Nota marginal: Idem.

15 Nota marginal: Idem.

16 Nota marginal: Idem.
} 
de la otra parte tierra de Lope Fernández, e de la otra parte tierras que fueron del gouernador Pedro de Vera.

${ }^{17}$ Otrosi, se le confirmó otras tres aransadas de tierra de riego que son en el barranco desta uilla, que an por linderos de la vna parte tierras de Juan Melián, y de la otra parte el río. La qual fue dada primeramente a Juan de Morales, e confirmósele con condiçión que si algún tienpo los herederos del dicho Juan de Morales vinieren demandando, pagándole la bienhechoria al dicho al dicho ${ }^{18}$ Fransisco de Cabrejas, la puedan tomar. Las quales dichas sinco arançadas de tierra se an de regar con el agua del barranco de la dicha villa por sus dulas, según que a suerte les a cabido.

${ }^{19}$ Otrosí, se les confirmó en el ualle que disen de los Cauallos sesenta fanegas de tierra de sequero de senbradura, que an por linderos de la vna parte tierras de Luis Martín, e de la otra parte la montaña, e de la otra parte tierras de Machín de Simadai.

[47r//] Fecho e sacado fue este dicho traslado de los dichos libros de repartimientos $y$ datas de tierras $y$ aguas que se hisieron en esta isla a los conquistadores y a otras personas, según que en ellas aparese, a que me refiero.

En Canaria, dose de mayo de mill y quinientos $y$ ochenta y ocho años. $Y$ fueron testigos al uer sacar y corregir con los oreginales Bernaldino de Palensuela y Lázaro de Mayuelo, vecinos desta isla.

$Y$ porque dello sean siertos, di el presente testimonio de pedimiento de Bernaldino de San Juan, regidor desta isla, como a nieto y uisnieto que dixo ser de los contenidos en este testimonio, que va firmado e signado de mi nombre e signo.

E por ende fise aqui este mío signo en testimonio de verdad. Alonso de Balboa, escrivano público y de Cabildo.

17 Nota marginal: Idem.

18 Sic.

19 Nota marginal: Idem. 